\title{
POSITION PAPER: Hepatitis B practice recommendations
}

\author{
This position statement was developed by IPAC Canada's Dialysis Interest Group: \\ Principal authors: Deborah Hobbs, RN, BScN, ClC; ${ }^{1}$ Colleen Weir, RN, BScN, CNeph(C), $\mathrm{ClC}^{2}$ \\ Affiliations: \\ ${ }^{1}$ Alberta Health Services; IPAC Canada - Alberta region, AB, Canada \\ ${ }^{2}$ Ottawa Hospital; IPAC Canada - Ottawa region, ON, Canada \\ Original date: \\ November 21, 2006 \\ Revised: \\ July 5, 2007; February 5, 2017; February 2018 \\ Published: \\ March 26, 2018
}

Hemodialysis patients are at high risk for acquiring bloodborne infections. The dialysis treatment requires large volumes of blood to be processed outside of the body. Contact either directly or indirectly with the contaminated environment, equipment, or hands of healthcare workers (HCWs) may result in the transmission of blood-borne pathogens [1].

Hepatitis B virus (HBV) is spread by percutaneous or permucosal exposure to blood or body fluids that contain HBV. $\mathrm{HBV}$ is relatively stable in the environment and can remain viable for at least seven days on environmental surfaces $[1,5]$. Hemodialysis programs should institute a comprehensive HBV prevention plan [1,4], including the recommendations provided below, and audits [6]. These recommendations address the prevention and management of HBV infection in hemodialysis patients. Other blood-borne pathogens (such as hepatitis $\mathrm{C}$ or HIV) do not require isolation. These patients are effectively managed through the implementation of routine practices [1-4].

\section{INFECTION PREVENTION AND CONTROL PRACTICE RECOMMENDATIONS FOR PREVENTION OF TRANSMISSION OF HEPATITIS B AMONG \\ HEMODIALYSIS PATIENTS}

1. Single-use injectable medications should be dedicated for use on a single patient and be entered one time only. Multi-dose vials should be avoided [7]. All parental medications should be prepared in a clean area separate from potentially contaminated items and surfaces [6].

2. Immunization

The risk of transmission of HBV is reduced by immunization [2].

- Patients: Hepatitis B vaccination is recommended early in the course of kidney disease for all susceptible patients. Beyond hemodialysis, this includes pre-dialysis and peritoneal dialysis patients. Kidney failure interferes with the body's natural immunity and chronic dialysis patients who become infected may become chronic carriers of the disease. Hemodialysis programs should have policies and procedures in place regarding revaccination and follow-up of immune status [1, 2, 4].
- Staff: HBV immunization of HCWs began in Canada in 1982 and is recommended for those persons at increased risk of occupational infection (i.e., those exposed to blood, blood products, and bodily fluids that may contain the virus) $[2,4,5]$. Hemodialysis programs should have a policy and procedures to monitor HCWs' HBV immunization.

- Test all who have been vaccinated for antibody to hepatitis B surface antigen (anti-HBs) one to two months after the last primary vaccine dose in order to determine their response to the vaccine (adequate response is defined as $>10 \mathrm{mIU} / \mathrm{mL})[2,4,5]$. Patients and staff members who do not respond to the primary vaccine series should be revaccinated with three additional doses and retested for response. No additional doses of the vaccine are warranted for those who do not respond to the second series $[2,4]$. In this case, follow recommendations for patients considered susceptible.

3. Containment and management

Contact transmission is the most important route by which pathogens are transmitted in healthcare settings [3].

- Consistently use routine practices for the care of all hemodialysis patients [3].

- Hand hygiene reduces the number of microorganisms on the hands and is the most important practice to prevent the spread of infection to patients and staff $[2,3,5]$.

- Personal protective equipment (PPE) - single use [2, 3, 5]:

- Gloves for direct patient care or when touching the patient's equipment. Perform hand hygiene prior to donning and after doffing gloves.

- Mask and eye protection or face shield to protect the mucous membranes of the eyes, nose, and mouth when performing procedures that may generate splashes or sprays of blood or body fluids.

- Gown to prevent soiling of clothing or unprotected skin.

- Standard facility-based environmental cleaning policies should be in place to reduce opportunities for transmission of infectious agents $[2,3,5]$. 
The following additional infection prevention and control practices should be taken with hepatitis B surface antigenpositive (HBsAg) patients:

- Dialyze HBsAg patients in a separate room with dedicated machine, equipment, medications, and supplies $[1,2,4]$.

- If a separate room is not available, a separate area may be used in order to geographically separate HBV-positive patients from HBV-susceptible patients [1, 2, 4].

- HCWs should not care for HBV-positive patients at the same time as HBV-susceptible patients [1, 4].

- HBV-immune patients may act as a geographical buffer between positive and susceptible patients [1, 4].

- Staff members can be assigned to care for both HBVpositive and HBV-immune patients on the same shift. There must be current serology to confirm the patient's HBV immunity prior to assigning the two groups together. Protection against HBV is not maintained if the patient's anti-HBs drop below protective levels of $10 \mathrm{mlU} / \mathrm{ml}[1,4]$.

4. Cleaning and disinfection

- The internal surface (previously, "pathways") of the dialysis machine used on an HBV-positive patient must be disinfected with a high-level disinfectant prior to use on another patient $[1,4]$.

- The external surface of the dialysis machine must be cleaned and disinfected with a facility-approved lowlevel disinfectant prior to use on another patient [1, 4].

- Following dialysis treatment, clean and disinfect all surfaces in the dialysis station with a facility-approved disinfectant, including the bed/chair, table, doorknobs, and television remote $[1,4]$.

- For centres with dialyzer reprocessing programs, dialyzers should not be reused on HBsAg-positive patients [1].

5. Screening

- Serologic testing of all chronic kidney disease patients should occur prior to admission to the program or at the first dialysis treatment (hemodialysis or peritoneal dialysis). This should include testing for $\mathrm{HBsAg}$, anti-HBs, and hepatitis B core antibody [4].

- If the patient's HBV status is unknown at the time of first treatment, the dialysis machine must not be used on another patient until the internal and external surfaces have been cleaned and disinfected [4].

- A method should be developed to monitor, review, evaluate, and communicate all serological testing for HBV [1, 4].

- Annual testing of all hemodialysis patients is required to determine immunity, susceptibility, and/or conversion. Susceptible patients should be tested more frequently until immunity has been established by vaccination. The frequency of testing $(\mathrm{Q}$ monthly, $\mathrm{Q}$ two months, or $\mathrm{Q}$ six months) will depend on the patient population and risk $[1,4]$.
- Programs should have a policy for follow-up and testing of susceptible patients who have received hemodialysis at other facilities (e.g., while travelling).

6. Education

- The hemodialysis program should have an educational plan for patients, their families, and advocates.

- This can be supported via education regarding the patient's role in infection prevention and control, including hand hygiene, access and wound cleaning, respiratory etiquette, and understanding/reporting signs and symptoms of infection [8].

- Ensure the patient has received appropriate education on the steps to prevent spreading the virus to others.

- Families and advocates should be educated by hemodialysis staff regarding what infection prevention measures they should expect to see taken by their dialysis team [8].

- The program should also provide educational opportunities for HCWs to gain knowledge and familiarity in $[1-3,5]$ :

- Transmission of blood-borne viruses.

- Interpretation of HBV serology.

- Routine practices, including hand hygiene and the donning and doffing of PPE.

- Additional transmission-based precautions (airborne, droplet, contact).

- Consultation with the institution's Infection Prevention and Control department for additional education regarding the appropriate management and prevention of HBV infection.

\section{GLOSSARY/DEFINITIONS}

As per the Canadian Standard Association:

"SHALL" is used to express a requirement, i.e., a provision that the user is obliged to satisfy in order to comply with the standard;

"SHOULD" is used to express a recommendation or that which is advised but not required; and

"MAY" is used to express an option or that which is permissible within the limits of the standard, an advisory or optional statement.

\section{REFERENCES}

1. Centers for Disease Control and Prevention. (2001). Recommendations for preventing transmission of infections among chronic hemodialysis patients. Morbidity and Mortality Weekly Report, 50(RR05), 1-43. Retrieved from https:// www.cdc.gov/mmwr/preview/mmwrhtml/rr5005a1.htm

2. Public Health Agency of Canada [formerly Health Canada]. (1997). Infection control guideline for preventing the transmission of bloodborne pathogens in health care and public service settings. Retrieved from http://publications. gc.ca/collections/collection_2016/aspc-phac/ HP3-1-23-S3-eng.pdf 
3. Public Health Agency of Canada [formerly Health Canada]. Centre for Communicable Diseases and Infection Control. (2017). Routine practices and additional precautions for preventing the transmission of infection in healthcare settings. Retrieved from https://www.canada.ca/en/public-health/ services/publications/diseases-conditions/routine-practicesprecautions-healthcare-associated-infections.html

4. Canadian Society of Nephrology. (2005). Recommendations from the ad hoc committee on the prevention of transmission of bloodborne pathogens in hemodialysis patients. Retrieved from https://www.csnscn.ca/images/Docs_Misc/ VAWG/The_Prevention_of_Transmission_of_Blood-_Borne_ Pathogens_in_Hemodialysis_Patients.pdf

5. Public Health Agency of Canada [formerly Health Canada]. (2002). Prevention and control of occupational health infections in health care. Retrieved from http://www.collectionscanada.gc.ca/webarchives/20071124130346/http://www. phac-aspc.gc.ca/publicat/ccdr-rmtc/02pdf/28s1e.pdf
6. Infection Prevention and Control Canada. (2018, February 5). IPAC Canada infection control audit toolkit. Retrieved from https://ipac-canada.org/ipac-canada-products-2. php\#audittoolkit

7. Centers for Disease Control and Prevention. (2008). Infection control requirements for dialysis facilities and clarification regarding guidance on parenteral medication vials. Morbidity and Mortality Weekly Report, 57(32), 875 876. Retrieved from https://www.cdc.gov/mmwr/preview/ mmwrhtml/mm5732a3.htm

8. Association for Professionals in Infection Prevention and Control and Epidemiology. (2010). Guide to the elimination of infections in hemodialysis. Retrieved from http://www.apic.org/Resource_/ EliminationGuideForm/7966d850-0c5a-48ae-9090-a1da00bcf988/File/APIC-Hemodialysis.pdf *

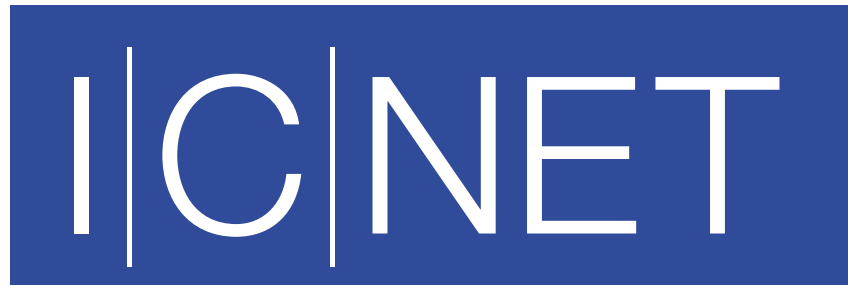

CLINICAL SURVEILLANCE SOFTWARE FOR INFECTION PREVENTION | PHARMACY | SURGICAL OUTCOMES

ICNet surveillance software provides you the insight to make more informed decisions on medication usage and infection control.

THE DATA YOU NEED. WHEN YOU NEED IT.

Visit www.baxter.ca for further information.

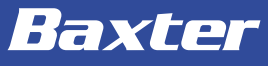

